\title{
Research Paper: Comparison of the Effectiveness of Mother's Mindfulness-based Cognitive Therapy and Cognitive Emotion Regulation Training on Externalizing Disorder and Self-efficacy of Aggressive Children
}

\author{
Afsane Shokri ${ }^{1}$, Reza Kazemi ${ }^{* *}$, Mohammad Narimani ${ }^{1,2}$, Somayye Taklavi
}

1. Department of Psychology, Ardabil Branch, Islamic Azad University, Ardabil, Iran.

2. Department of Psychology, Faculty of Psychology and Educational Sciences, University of Mohaghegh Ardabili, Ardabil, Iran.

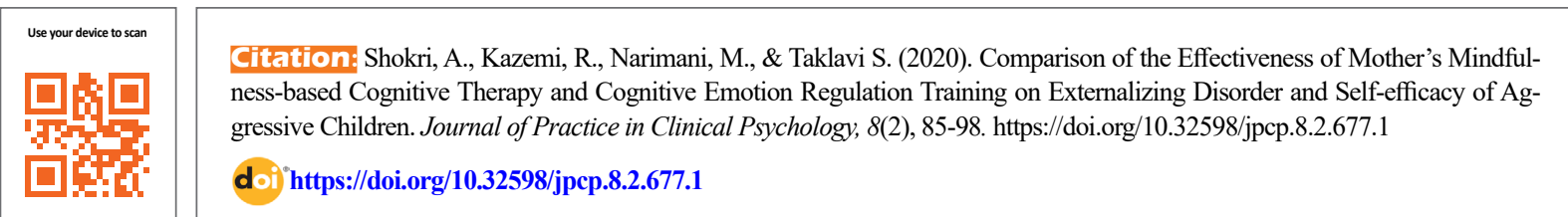

\section{(i) (3)}

Article info:

Received: 10 Nov 2019

Accepted: 23 Feb 2020

Available Online: 01 Apr 2020

Keywords:

Aggression, MindfulnessBased Cognitive Therapy, Cognitive emotion regulation training, Externalizing disorders, Self-efficacy

\section{ABSTRACT}

Objective: This study aimed to compare the effectiveness of the mother's mindfulness-based cognitive therapy and cognitive emotion regulation training on externalizing disorder and selfefficacy of aggressive children.

Methods: The research method was a quasi-experimental study with a pre-test/post-test design and a control group. The study population $(\mathrm{N}=540)$ included all female students in the primary schools in Namin City, Iran in 2018 with their mothers. A multistage clustering random sampling was used to choose the students under study, and a total of 217 students were selected as the samples and the aggression questionnaire was completed by the teachers. Of these students, 79 students who scored high on the Shahim's aggression scale were selected as aggressive students and 60 mothers of these students were selected by considering the inclusion criteria and were assigned randomly in three groups of 20 mothers each. The mindfulness-based cognitive therapy and cognitive emotion regulation training were executed in the experimental groups in 8 sessions, whereas the control group received no intervention. Before and after the intervention, all three groups responded to Shahim's relational aggression scale, Sherer and Adam's general self-efficacy, and Achenbach and Rescolar's child behavior checklist. The obtained data were analyzed by multivariate analysis of covariance.

Results: The calculated values showed that mindfulness-based cognitive therapy was more effective $(\mathrm{P}>0.05)$ than cognitive emotion regulation training.

Conclusion: the findings of this study suggest that mother's mindfulness-based cognitive therapy can be an effective intervention in reducing externalizing disorders and increasing self-efficacy in aggressive children.

\section{* Corresponding Author:}

Reza kazemi, $M D$.

Address: Department of Psychology, Ardabil Branch, Islamic Azad University, Ardabil, Iran.

Tel: +98 (914)1525726

E-mail:dr_reza.kazemi@yahoo.com 


\section{Highlights}

- The calculated values showed that mindfulness-based cognitive therapy was more effective than cognitive emotion regulation training.

- Mother's mindfulness-based cognitive therapy can be an effective intervention in reducing externalizing disorders and increasing self-efficacy in aggressive children.

- There are significant differences between aggressive children in two experimental groups.

\section{Plain Language Summary}

Aggression is a behavior that is threatening and possibly harmful. It may be expressed verbally (such as threatening) or physically (such as hitting, biting, or throwing objects at someone else). Research shows that parental mental disorder, especially mothers and dysfunctional parent-child relationships play a decisive role in the aggression of children. So interventions that targeting parents are effective ways to prevent this disorder. The present study was conducted on 60 aggressive children with their mothers in Namin City to compare the effectiveness of mindfulness-based cognitive therapy and cognitive emotion regulation training on externalizing problems and self-efficacy of aggressive children. As a result, mothers' mindfulness-based cognitive therapy had more effectiveness in reducing externalizing disorders and increasing self-efficacy in aggressive children.

\section{Introduction}

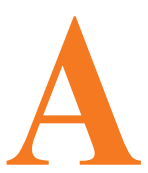

ttention to children's problems is a global and widespread problem. A major part of the world's population is children, as in developing countries, $50 \%$ of people are children (Jarareh, Mohammadian, Nader, Mosavian, 2016). The fact is that although a process of change that is always accompanied by the rapid change may not have behavioral stability, it is clear that many children have emotional and behavioral problems in their early childhood that develop over time and perhaps continue until adolescence and even adulthood. One of these problems is aggression, which involves behavior that is threatening and possibly harmful. The aggression may be expressed verbally (such as threatening) or physically (such as hitting, biting, or throwing objects at someone else) (Fitzpatrick, Srivorakiat, Wink, Pedapati, \& Erickson, 2016). The concept of aggression includes acts such as physical aggression, verbal and non-verbal behavior, or symbolic acts against others (Jarareh, Mohammadian, Nader, Mosavian, 2016). Because of the rapid spread of aggression in recent years, the investigation of the causes and control of aggression has drawn the attention of psychologists. Childhood aggression is common, transdiagnostic, and strongly correlated with other externalizing and internalizing problems, including attentional difficulties, rule-breaking behaviors, depression, anxiety, and sleep disorders (Scott, Tunbridge, Stathis, 2018). In this regard, ex- ternalizing disorders, which are among the childhood disorders, are characterized by problematic behaviors related to poor impulse-control, including rule-breaking, aggression, impulsivity, and inattention (Samek \& Hicks, 2014). In the fifth edition of the Diagnostic and Statistical Manual of Mental Disorders, there is no definite class for externalizing disorders and it is mentioned in the form of three disorders: attention-deficit/hyperactivity disorder, oppositional defiant disorder, and conduct disorder (Krueger, Markon, Patrick $\&$ Iacono, 2005). Child and adolescent externalizing disorders are relatively common, with estimates ranging from $7 \%$ to $10 \%$ and with higher prevalence in males relative to females (Samek \& Hicks, 2014).

On the etiology of these disorders, many factors have been proposed. Patterson, DeBaryshe \& Ramsey (1989) have reported an influential theory of antisocial behavior. It is a model of the behavioral contingencies between parents and children in which each "trains" the other to respond in ways that will increase and maintain a child's aggressive and oppositional behavior while simultaneously decreasing parents' control over such behaviors. Parents who employ ineffective parenting practices, such as inconsistent discipline, ultimately reinforce aggressive behaviors. So the concept of parent-child interaction has been raised. The quality of parental relationships, especially the mother-child relationship, has a decisive role in shaping the social personality, cognitive function, and mental health of the child in the future. The long-term effects have been proven to affect 
the growth and development of the child Messmer et al. (1997). So it plays a crucial role in the development of the child's psychological and emotional characteristics. Some research has focused on the active role of parental behavior, most notably, the lack of parental involvement, poor management and supervision, violent and unstable discipline (Satoorian, Tahmassian, \& Ahmadi, 2016) and parenting problems and maternal stress (Weijers, van Steensel \& Bögels, 2018). Esehaghzadeh, Reyhani, Moharari, \& Mazlom (2018) reported that training positive parenting programs on the mother-child relationship can improve the mother-child relationship in mothers of children with externalizing disorders and reduce symptoms of externalizing disorders.

Another factor that might be important in the development of externalizing behavior problems is a sense of self-efficacy for the control of emotionally-driven behaviors (Samson, 2009). Self-efficacy refers to "beliefs in one's capabilities to organize and execute the courses of action required to produce given attainments" (Yin, Han, \& Perraon, 2020). Selfefficacy is the belief we have about our abilities (Bendura; cited in Schultz \& Schultz, 2006). Although some literature reported that self-efficacy is related to aggressive behavior, the mechanism whereby self-efficacy affects aggressive behavior has remained unclear. Perry, Perry, and Rasmussen (1986) and Gottheil and Dubow (2001) suggest that a relationship exists between perceived self-efficacy for inhibiting aggressive behavior and actual behavior, but they do not attempt to explain why inhibiting aggressive behavior might be related to the ability to produce appropriate behaviors in a social situation. Some studies have reported a negative relationship between aggression and self-efficacy (Allameh, Shahani Yeylagh, Haji Yakhchali, \& Mehrabizadeh Honarmand, 2015; Liorca, Richaud \& Malonda, 2017). Also, the research exploring the interaction between self-efficacy and aggression is absent in the literature (Crick \& Dodge, 1996; Hubbards, Morrow, \& Romano, 2010). Studies are supportive of the hypothesis that adolescents who believe in themselves capable of carrying out aggressive behavior are more likely to engage in such behavior (Camodeca \& Goossens, 2005; Hubbard, McAuliffe, Morrow, \& Romano, 2010). But little is known whether this capability relates to aggression in particular or just aggression in general. The reason for these conflicting findings could be related to the fact that many of the recent studies have focused solely upon either physical or relational types of aggression (Crick \& Grotpeter, 1995; Farrell, Bettencourt, Mays, Kramer, Sullivan, \& Kliewer, 2012; Gottheil \& Dubow, 2001; Werner \& Nixon, 2005). Since the family environment and the type of the relationships between parents and their children have a direct relation with children's perceptions of self-efficacy (Antony \& Manikandan, 2016), it seems that parents training about the relationships with children improves interpersonal re- lationships with them and affect children's self-efficacy (Riahi, Esmaili, \& Kazemian, 2016).

Today, psychoanalysts use a variety of therapies to control and reduce aggressive behaviors, including Mindfulness-Based Cognitive Therapy (MBCT) (Mace, 2008). This therapy requires specific behavioral, cognitive, and metacognitive strategies to focus the attention process which in turn leads to the avoidance of factors producing negative mood, negative thinking, a tendency to worrying responses, and the development of new perspectives and the formation of pleasant thoughts and emotions (Segal, Williams, \& Teasdale, 2002). MBCT practice reduces the abnormal habitual reactions of parents, which in turn reduces hostility, coercion, excessive parental control, and inappropriate parenting behaviors, while increases positive patterns such as honest communication, warmth, and acceptance with children that ultimately lead to higher child mental health (Bogels, Hellemans, van Deursen, Romer \& van der Meulen, 2013).

In this method, people learn to accept their life events in a specific, purposeful, systematic way far from prejudice and judgment, before succumbing to the accidents and events of their lives (Shearer, Hunt, Chowdhury \& Nicol, 2016). The basic assumption of the MBCT implies this important point that any thought that is taken into consideration by individuals should not be accepted as an influential factor of pure reality. This type of mindfulness is a kind of preventative response to thoughts that make people anxious and aggressive. This method helps individuals to return to the equilibrium that existed before experiencing negative emotions (Kim et al., 2009). Various studies have shown the effectiveness of MBCT for mothers on reducing child aggression (Bader, Barry, \& Hann, 2015; Parent, McKee, Rough, \& Forehand, 2016; Corthorn, 2018). Hamidian, Amiri, Pour Abolghasemi, Naziri, and Mousavi Nasab (2016) found in a study that MBCT and medication had a more significant role in reducing anger and aggressive behaviors compared with mere medication.

On the other hand, many children's disorders, including physical, cognitive, behavioral, and emotional disorders are influenced by mothers' emotional distress (Chew, Zain, \& Hassan, 2013), that is, mothers with high levels of stress and emotional problems show weaknesses in coping with parental roles and, as a result, face difficulties in upbringing children that lead to increased behavioral disorders, including aggression in the child (Waters Virmani, Thompson, Meyer, Abigail Raikes, \& Jochem 2010). Thus, one of the other interventions that may be effective in this regard is cognitive emotion regulation 
training. Teaching parents' emotional management skills reduces the use of negative emotional strategies to cope with children's behavioral problems and stressful situations, which will lead to their emotional wellbeing and future educational success (Aldao, Nolen-Hoeksema \& Schweizer, 2009). In this regard, the results of the research by Beirami, Hashemi, Bakhshi Pour, Alilo, and Eqbali (2014) and Kamali, Vaghei, Asgharipour and Behnam (2016) have shown that emotion regulation training has a significant effect on mothers' health. Besides, the results of the research by Roberton, Daffern, and Bucks (2012) and Gowdini, Pourmohamadzrezaye Tajrishi, Tahmasebi, and Biglarian (2017) have shown that mothers' emotion regulation training impacts their children's behavioral problems. Other studies have also shown that emotion regulation training reduces externalizing behaviors (Van Aken, Junger, Verhoeven, van Aken, Deković, \& Denissen, 2007; Gavita, David, Bujoreanu, Tiba and Ionutiu, 2012; and increases selfefficacy (Walsh, 2013; Akhlaghi, Yazdi Nejad, Hosseini Sabet, \& Borjali, 2017).

Despite the mothers' critical role in children's mental health and the success of parent-centered strategies for improving children's behavioral problems, no research considers parenting problems as central to the development of child behavioral problems. Besides, most research backgrounds have been conducted on male children and based on overt aggression, and the treatment is done on the children, not their mother. However, in recent years, childhood and adolescent psychologists have focused on relationship aggression, which is more prevalent in girls, and in the treatment of child aggression, on preventive measures and parental empowerment interventions (Leff, \& Crick, 2010). Attention to the limitations and high prevalence of behavioral disorders in children, negative effects of behavioral disorders on individual and family performance and maternal role in children's behavioral problems, due to the current research vacuum in our country and lack of comprehensive research to compare the effectiveness of mindfulness-based cognitive therapy and cognitive emotion regulation training to identify the most effective way to reduce behavioral problems in aggressive children. So, the present study aims to answer these questions:

How much is the effectiveness of the mother's mindfulness-based cognitive therapy and cognitive emotion regulation training on externalizing problems and selfefficacy in aggressive children?

What is the difference between the effectiveness of these two therapies?

\section{Methods}

The research method was a quasi-experimental study with a pre-test/post-test design and a control group. The statistical population included all female students in elementary school in 2018 in Namin City, Iran ( $\mathrm{N}=540)$ along with their mothers $(\mathrm{N}=540)$. A multistage clustering random sampling was used to select the students under study. So, from the girls' schools of Namin, 3 schools were randomly selected and 9 classes from these 3 schools and a total of 217 students were randomly selected as the prototype and the aggression questionnaire was completed by the teachers. Of these students, 79 students who scored above average (one standard deviation) in the aggression questionnaire were selected as aggressive students, and mothers of these students were also chosen for the sample in this research. Ultimately, a sample of 60 mothers was selected by considering inclusion criteria and were assigned randomly in three groups of 20 mothers each.

The experimental groups' mindfulness-based cognitive therapy and cognitive emotion regulation training were executed in 8 sessions, whereas the control group had no intervention. The inclusion criteria for mothers using clinical interview based on DSM5 were lack of received psychological treatment during the last 6 months, willingness and informed consent to participate in the research project, literacy, age between 20 and 50 years, lack of severe psychiatric disorders and use of psychotropic drugs, and having a 10-12 years old student with no physical or mental disability. The exclusion criteria for mothers were absenteeism of at least two sessions from training sessions and failure to perform sessions.

\section{Study tools}

\section{Shahim's Relational Aggression Scale}

This questionnaire was developed by Shahim (2007) and has 21 items and is scored on a 4-point Likert scale. The relational and explicit aggression scale has three subscales of physical aggression, verbal and hyperactive reactive aggression, and relational aggression. This questionnaire is completed by the trainer. The reliability of this questionnaire was estimated by using the Cronbach alpha coefficient for physical, relational, and reactive and hyperactive aggressions as $0.85,0.89$, and 0.83 , respectively, and estimated to be 0.91 for the whole scale. The validity of this questionnaire was assessed by using factor analysis with principal axis analysis and oblique rotation to extract three factors with a specific value above 1 , which explained $59 \%$ of the variance. The KMO coefficient was 0.12 and Bartlett test result was significant 
for the sphericity of the data. The correlation coefficient between items and the total score of physical aggression components ranged from 0.47 to 0.82 . The correlation coefficient between relational aggression and total score varied from 0.84 to 0.67 , and the correlation coefficient between items and the total score of the reactive and hyperactivity aggression component varied from 0.2 to 0.63 (Shahim, 2007).

\section{Sherer and Adams General Self-Efficacy Scale}

This scale was developed by Sherer and Adams (1983) and has 19 items and each item has 5 choices. Thus the items number $1,3,8,9,13,15$, which are rated on a Likert-type scale get scores from 5 to 1 , respectively and the rest of the items, i.e., the items number $2,4,5,6,7$, $10,11,12,14,16$, and 17 get scores from 1 to 5 . The highest self-efficacy score on this scale is 85 and the lowest score is 17 . The Cronbach alpha reliability coefficient was reported at 0.74 (Sherer \& Adams, 1983). Wood- ruff and Cashman (1993) also confirmed the validity and reliability of this scale. The internal consistency of this scale is 0.83 and its correlation with Rotter's locus of control coefficient as a criterion validity study was reported 0.5. In Iran, Mehrabi Zadeh Honarmand, Abolghasemi, Shokrkon, and Najarian (2000) reported that the Cronbach alpha coefficient and self-efficacy scale split coefficient were 0.81 and 0.79 , respectively. Arabian (2004) reported a correlation between self-esteem and self-assessment with a self-efficacy scale of 0.01 to evaluate validity.

\section{Child behavior Checklist (CBCL)}

This checklist was developed by Achenbach and Rescolar in 2001. Child Behavior Checklist (CBCL) has been formulated for children and adolescents aged 6-18 years. CBCL must be completed by the parent or guardian of the child. The part of the checklist that measures emotional-behavioral problems consists of 113

Table 1. Mindfulness-Based cognitive therapeutic sessions (Segal, Williams, \& Teasdale, 2002)

\begin{tabular}{|c|c|}
\hline Session & Objectives and Contents \\
\hline First session: Automatic pilot & A practice session of eating a raisin mindfully with meditation \\
\hline $\begin{array}{l}\text { Second session: Dealing with } \\
\text { barriers }\end{array}$ & Practicing meditation; ten minutes of mindfulness on breathing \\
\hline $\begin{array}{l}\text { Third session: } \\
\text { Mindfulness of the breath }\end{array}$ & $\begin{array}{l}\text { Mindfulness on breathing (and on the body at the time of movement); movement exercise with } \\
\text { the mindful state, breathing and stretching exercises and mindful exercise followed by meditation } \\
\text { in a sitting position focused on the consciousness of body and breath, these exercises can begin } \\
\text { with a brief exercise of the visual or auditory mindfulness, three minutes of breathing space }\end{array}$ \\
\hline $\begin{array}{l}\text { Fourth session: } \\
\text { Staying present }\end{array}$ & $\begin{array}{l}\text { Practicing five-minute meditation sessions with visual or auditory mindfulness; sitting medita- } \\
\text { tion (awareness of breathing, body, sounds, thoughts, and consciousness without specific ori- } \\
\text { entation), three-minute breathing space, introducing the method as a coping strategy for use at } \\
\text { times when situations arouse difficult feelings, mindful walking }\end{array}$ \\
\hline $\begin{array}{l}\text { Fifth session: Allowing/Let- } \\
\text { ting be }\end{array}$ & $\begin{array}{l}\text { Sitting meditation practices; awareness of breathing and body, emphasis on understanding how } \\
\text { to react to thoughts, emotions and physical causes created, introducing a difficult situation in } \\
\text { practice and exploring its effects on body and mind, and three minutes of breathing space }\end{array}$ \\
\hline $\begin{array}{l}\text { Sixth session: Thoughts are } \\
\text { not facts }\end{array}$ & $\begin{array}{l}\text { Sitting meditation practice; breathing and body awareness, plus introducing exercise-related } \\
\text { problems and understanding its effects on the body and mind; three minutes of breathing space }\end{array}$ \\
\hline $\begin{array}{l}\text { Seventh session: How can I } \\
\text { best take care of myself }\end{array}$ & $\begin{array}{l}\text { Meditation exercises in sitting position; awareness of breathing, body, sounds, thoughts, and } \\
\text { emotions; three minutes of breathing space, and a plan to perform the task and find out its ef- } \\
\text { fects on body and mind }\end{array}$ \\
\hline $\begin{array}{l}\text { Eighth session: Using what } \\
\text { has been learned to deal with } \\
\text { future moods }\end{array}$ & Meditation session exercises, meditation completion \\
\hline
\end{tabular}


Table 2. Therapeutic sessions of cognitive emotion regulation

\begin{tabular}{|c|c|}
\hline Session & Objectives and Contents \\
\hline First & Introducing group members to each other \\
\hline Second & Explain the logic and stages of intervention and the framework and rules for participating in the group \\
\hline Third & $\begin{array}{l}\text { Recognizing emotions and motivating situations through teaching the differences between various types of emotions } \\
\text { and the short-term and long-term effects of emotions }\end{array}$ \\
\hline Fourth & Assessing the extent of vulnerability and emotional skills of members \\
\hline Fifth & $\begin{array}{l}\text { Making changes in the emotion-arousing situation and training of interpersonal skills (dialogue, the assertion of exis- } \\
\text { tence, and conflict resolution) }\end{array}$ \\
\hline Sixth & Changing the focus and stopping the rumination and worry \\
\hline
\end{tabular}

Seventh Changing cognitive assessments and teaching reassessment strategies

Eighth Changing behavioral and physiological consequences of emotion, reassessment, and removal of barriers to use

main questions and 8 sub-questions that are scored on a 3 -point scale $(0=$ not true, $1=$ partially or sometimes true, $2=$ completely or often true). This checklist measures 8 emotional or behavioral problems or syndromes, including anxiety/depression, loneliness/depression, physical complaints, social problems, thinking problems, attention problems (inattention, hyperactivity, and impulsivity), violent behavior, and aggressive behavior. Seventeen items do not belong to any of these syndromes and are classified as "other problems." The retest of the reliability was reported to be 0.94 for the whole checklist, 0.91 for violent behavior, and 0.90 for aggressive behavior. The Cronbach alpha value was 0.97 for the whole checklist, 0.85 for violent behavior, and 0.94 for aggressive behavior (Achenbach and Rescolar, 2001). Also, Achenbach (1991) evaluated the correlations of this scale with two scales of "Conners' behavior rating scale" and "Quay-Peterson revised behavior problem checklist" and found them between 0.52 and 0.88 . Yazdkhasti and Oreyzi (2011) calculated the Cronbach alpha coefficients for this questionnaire in three forms of "parent", "teacher", and "child", as 0.90, 0.93 and 0.82, respectively and the construct validity of the subscales of the behavioral-emotional problems section with the overall score of this section in the three forms of "parent", "teacher", and "child" reported as 0.62-0.88, 0.44-0.91, and $0.51-0.85$, respectively. Minaei (2007) reported the intrinsic correlation of this checklist ranging from 0.50 to 0.81 , all of which were significant at the 0.01 level. A confidence interval of 0.95 around these correlations indicated that none of the syndromes overlap completely, indicating the diagnostic validity of these syndromes.

\section{Mindfulness-Based Cognitive Therapy Program}

This program was designed by Segal, Williams, and Teasdale (2002) based on behavioral techniques of relaxation and meditation. The contents of the therapy sessions are as follows (Hillgaar, 2011) (Table 1).

\section{James Gross's cognitive emotion regulation protocol}

The various stages of emotion regulation training based on this package were in the form of eight 2-h sessions (Gross, 2007) (Table 2).

\section{Study procedure}

To implement this research, after acquiring the necessary permits, the researcher referred to the Education Office of Namin City in 2018 and took the list of girl's elementary schools and the number of students in these schools. After the determination of aggressive students by multistage clustering randomly sampling method, the mothers of these students were asked to attend school and obtained their consent for holding treatment sessions and the initial interview was conducted to investigate the inclusion criteria. Then the mothers were assigned to two experimental groups and one control group. The subjects 
were given written consent to participate in the study and were asked to participate in the course of treatment. Initially, all three study groups were pretested and mothers were asked to complete the child behavior checklist and their children to complete the Scherer-Adams general self-efficacy questionnaire. At the end of the treatment period, the two experimental groups and one control group were assessed again (post-test).

The treatment comprised eight 120-minute sessions, and a weekly session was performed by the researcher in a group manner. During the implementation of training and treatment sessions, all subjects of the experimental group were present and none of the programs were canceled. It should be noted that all ethical considerations such as information confidentiality and parental satisfaction were observed in the implementation of this study. The data were analyzed using the multivariate analysis of covariance with SPSS V. 20.

\section{Results}

According to the collected data, 55\% of participants were in the age range of 20 to 35 years, and $45 \%$ were in the age range of 36 to 50 years. The Mean \pm SD age of the mindfulness training group was $33.90 \pm 6.43$ years. It was $36.55 \pm 4.334$ years for the cognitive emotion regulation training group and $35.50 \pm 6.074$ years for the control group. The total Mean \pm SD age of the participants was $35.32 \pm 5.697$ years. Besides, $18.3 \%$ of the participants had primary education, $41.7 \%$ secondary education, $23.3 \%$ a diploma, and $16.7 \%$ a university education (Table 3 ).

According to Table 3, the participants' post-test scores on externalizing problems in mindfulness and emotion regulation training groups were lower than those in the control group. Also, the participants in the mindfulness training group received a lower mean of externalizing problems than the emotion regulation training group. Besides, post-test self-efficacy scores of subjects in mindfulness training and emotion regulation training groups were higher than those in the control group participants, and the scores of the subjects of mindfulness training group had a higher average level than emotion regulation group.

We employed multivariate analysis of covariance to analyze the data and the Kolmogorov-Smirnov test was used to test the assumption of normality of distribution of scores before performing covariance analysis. The results of the Kolmogorov-Smirnov test indicated the normal distribution of the data for externalizing problems and its components and self-efficacy variables for all three groups in the pre-test and post-test stages $(\mathrm{P}>0.05)$.
In addition, the assumption of homogeneity of variances was examined and confirmed by Levene's test. Also, the assumption of homogeneity of the slope of the regression line and the existence of a linear relationship between the covariate and the dependent variable was investigated, and the results indicated that these two assumptions were true. Besides, by controlling for the pre-test effect, the significant level of Wilks' lambda test indicated a significant difference between the experimental and control groups in at least one component of externalizing and self-efficacy problems. This issue indicates that the observed difference in the means of these variables is related to the effect of mindfulness-based cognitive therapy approaches and cognitive emotion regulation training.

The results of Table 4 show that considering pre-test scores as a covariate variable, mindfulness-based cognitive therapy interventions, and cognitive emotion regulation training resulted in a significant difference between the groups in violent behavior $(\mathrm{F}=22.29 ; \mathrm{P}<0.448)$, aggressive behavior $(\mathrm{F}=27.20 ; \mathrm{P}<0.497)$, and children's self-efficacy $(\mathrm{F}=31.00 ; \mathrm{P}<0.525)$. The impact rate was $44.8 \%$ for violent behavior and $49.7 \%$ for aggressive behavior, and the self-efficacy was $52.5 \%$. As a result, part of the individual differences in the dimensions of externalizing problems and self-efficacy are due to differences in group membership (intervention effect). This means that mindfulness-based cognitive therapy and cognitive emotion regulation training influence the externalizing problems in aggressive children. Next, the Least Significant Difference (LSD) paired comparisons test was used to examine the difference between the mean of the experimental and control groups, the results of which are presented in Table 5.

The results of the LSD follow-up test in Table 5 show that in the components of violent behavior, aggressive behavior, and self-efficacy, the difference between the mean mindfulness-based cognitive therapy, emotion regulation training, and control groups, favored the mean cognitive-based therapy and emotion regulation training groups (compared with the control group). In other words, participants in the mindfulness-based cognitive therapy and emotion regulation training groups had lower scores than the control group on the components of violent and aggressive behavior.

\section{Discussion}

The purpose of this study was to compare the effectiveness of mothers' mindfulness-based cognitive therapy and cognitive emotion regulation training on externalizing problems and self-efficacy in aggressive children. Based 
Table 3. Descriptive statistics of variables in the study groups

\begin{tabular}{ccccccc}
\hline \multirow{2}{*}{ Variable } & \multicolumn{5}{c}{ Mean \pm SD } \\
\cline { 2 - 7 } & \multicolumn{2}{c}{ Mindfulness Group } & \multicolumn{2}{c}{ Emotion Regulation Group } & \multicolumn{2}{c}{ Control Group } \\
\cline { 2 - 7 } & Pre-test & Post-test & Pre-test & Post-test & Pre-test & Post-test \\
\hline Violent behavior & $23.10 \pm 3.62$ & $19.50 \pm 2.70$ & $22.20 \pm 3.31$ & $19.85 \pm 3.06$ & $22.65 \pm 3.11$ & $21.65 \pm 2.58$ \\
\hline Aggressiveness & $26.10 \pm 3.38$ & $21.15 \pm 2.72$ & $23.85 \pm 3.66$ & $20.45 \pm 2.92$ & $24.40 \pm 3.08$ & $23.00 \pm 2.77$ \\
\hline Externalizing problems & $49.20 \pm 5.4$ & $40.65 \pm 3.57$ & 46.4 .05 & $40.30 \pm 3.81$ & $47.05 \pm 4.29$ & $44.65 \pm 3.89$ \\
Self-efficacy & $53.95 \pm 5.09$ & $59.25 \pm 5.21$ & $54.40 \pm 4.87$ & $57.85 \pm 4.35$ & $55.05 \pm 4.40$ & $56.70 \pm 4.10$ \\
\hline
\end{tabular}

Table 4. Results of the covariance analysis of the intergroup effects of mean externalizing problems and self-efficacy

\begin{tabular}{|c|c|c|c|c|c|c|c|}
\hline Components & Source of Changes & $\begin{array}{c}\text { Mean } \\
\text { Squares }\end{array}$ & df & $\begin{array}{l}\text { Mean } \\
\text { Squares }\end{array}$ & $\mathbf{F}$ & $\mathbf{P}$ & Eta Coefficient \\
\hline \multirow{3}{*}{ Violent behavior } & Group $\times$ pre-test & 5.84 & 2 & 2.92 & 2.17 & 0.125 & 0.078 \\
\hline & Group & 61.03 & 2 & 30.51 & 22.29 & 0.0001 & 0.448 \\
\hline & Error & 75.29 & 55 & 1.36 & & & \\
\hline \multirow{3}{*}{$\begin{array}{l}\text { Aggressive } \\
\text { behavior }\end{array}$} & Group $\times$ pre-test & 0.240 & 2 & 0.120 & 0.071 & 0.932 & 0.003 \\
\hline & Group & 97.07 & 2 & 48.53 & 27.20 & 0.0001 & 0.497 \\
\hline & Error & 98.13 & 55 & 1.78 & & & \\
\hline \multirow{3}{*}{ Self-efficacy } & Group $\times$ pre-test & 5.22 & 2 & 2.61 & 1.31 & 0.278 & 0.046 \\
\hline & Group & 124.85 & 2 & 62.42 & 31.00 & 0.0001 & 0.525 \\
\hline & Error & 112.73 & 56 & 2.013 & & & \\
\hline
\end{tabular}

Table 5. Least significant difference follow-up test results for paired comparison of mean externalizing problems between groups

\begin{tabular}{|c|c|c|c|c|c|}
\hline \multirow[t]{2}{*}{ Variable } & \multicolumn{2}{|c|}{ Group } & \multirow{2}{*}{$\begin{array}{c}\text { Mean Difference } \\
-1.052^{*}\end{array}$} & \multirow{2}{*}{$\begin{array}{c}\text { Standard Error } \\
0.387\end{array}$} & \multirow{2}{*}{$\begin{array}{c}\text { Significance } \\
0.009\end{array}$} \\
\hline & Mindfulness & Emotion regulation & & & \\
\hline \multirow{3}{*}{$\begin{array}{l}\text { Violent be- } \\
\text { havior }\end{array}$} & Mindfulness & Control & $-2.506^{*}$ & 0.379 & 0.0001 \\
\hline & Emotion regulation & Control & $-1.454^{*}$ & 0.372 & 0.0001 \\
\hline & Mindfulness & Emotion regulation & $-0.897^{*}$ & 0.442 & 0.047 \\
\hline \multirow{3}{*}{$\begin{array}{l}\text { Aggressive } \\
\text { behavior }\end{array}$} & Mindfulness & Control & $-3.067^{*}$ & 0.433 & 0.0001 \\
\hline & Emotion regulation & Control & $-2.171^{*}$ & 0.424 & 0.0001 \\
\hline & Mindfulness & Emotion regulation & $1.809^{*}$ & 0.449 & 0.0001 \\
\hline \multirow[t]{2}{*}{ Self-efficacy } & Mindfulness & Control & $3.549^{*}$ & 0.451 & 0.0001 \\
\hline & Emotion regulation & Control & $1.741^{*}$ & 0.449 & 0.0001 \\
\hline
\end{tabular}

* Significance level at 0.05 
on the literature, aggression, self-efficacy, and externalizing disorder are associated with each other. The present study showed that these two methods had different effects on externalizing problems and self-efficacy in aggressive children in the post-test stage. Also, mindfulness-based cognitive therapy, compared with the cognitive emotion regulation, was more effective on mothers who can reduce the aggression of their children. This finding is consistent with the results of Werner, Nixon (2005), Samson (2009), Riahi et al. (2016), Parent et al. (2016), and Corthorn (2018). They have shown that mindfulness-based cognitive therapy has effects on mothers in reducing externalizing problems and increasing children's self-efficacy and subsequently reducing aggression.

Similar to previous studies (Werner \& Nixon, 2005), significant relationships were found between aggression (externalizing disorder) and self-efficacy. This finding demonstrates that aggression may influence externalizing problems behavior. Farrell et al. (2012) suggested that adolescents who are demonstrating a strong belief in the use of aggression would be at greater risk for aggressive behavior because they believe that aggressive behavior is a justified way to assert social dominance. These findings also support hypotheses in Table 4.

Results of the present study are consistent with Bögels, Hoogstad, van Dun, de Schutter, \& Restifo (2008) results, in which the parents reported improvement in relationships with adolescents suffered from externalizing behavior problems, after mindfulness-based cognitive therapy and mindful parenting. In explaining this result, it can be said that mindfulness practices enhance social connectedness and skills and perspective-taking (Naseh, Heydarinasab, Shairi, 2016). In other words, mindfulness may lead to a significant shift in perspective, thereby contributing to individuals' behavior change and positive development outcomes. Indeed, substantial empirical studies have demonstrated that dispositional mindfulness has important implications for individuals' psychological functioning (Zang, Wang, \& Ying, 2019). Besides, it can provide practical and attitudinal skills for a more positive encounter with conflict. Also, it appears that mothers with mindfulness training could promote structural and functional changes in neural circuits that regulate physiological and emotional responses, and improve the capacity for empathy, which in turn can lead to non-reactional and compassionate responsiveness and a reduction in impulsivity in children. Therefore, mindful mothers are more efficient without bias and with a mere consideration of the external event. As a result, it can be effective in increasing the effectiveness of these mothers in dealing with aggressive children while simultaneous- ly affecting the effectiveness of mothers in bringing up their children, most likely showing itself in the process of initiating positive feedback and a more efficient cycle in the relationship between mother and child. On the other hand, mothers having aggressive children, feeling depressed, and lacking incompetence (which illustrates a sense of inadequacy and inability to perform parental duties,), have the most parental stress.

Therefore, The cognitive approach used in this intervention promotes mothers' self-awareness, helps them to identify their strengths and weaknesses, and changes their attitudes and beliefs. Mindfulness skills increase mothers' ability to deal effectively with negative moods and help them employ more effective ways of resolving conflict. In addition to this mindfulness and besides judgment, it also includes other factors such as observation and ability to describe and name experiences and feelings, conscious performance and activities in the present and attention, all of which can be vital to improving the mental health of all people, but they are more important in the family and people in emotional situations (Hosseinzadeh, Kakavand, \& Ahmadi, 2016). It can be concluded that in this study, the components cognitive fusion (according to its purpose concerning the reduction in the true sense of inner experiences and also, attention to thoughts just as thought), mindfulness (benefits for reducing frequency and intensity of conflicts between mother-child) and are the most influential factors in reducing children's externalizing symptoms (Naseh, Heydarinasab, Shairi, 2016).

Parents' awareness of themselves and their thoughts and emotions about their children helps them to develop a relaxed relationship in expressing positive and warm feelings with their children. This relationship affects parents' beliefs and expressions about emotions and the ways they deal with their children's emotional level. In other words, the amount of interactions, communications, and acceptance of emotions are at their peak. In such families, one can regulate appropriate emotions and avoid negative emotions such as aggression.

Moreover, the use of parent training program (mindfulness) especially by mothers for externalizing problems can improve the parenting style, mother-child relationship, and decrease maternal depression, anxiety, stress, and children's misbehavior. This program can reduce the behavioral problems of children and prevent stress in a child-parent relationship, improve the mother's mental health, and decrease externalizing behavior in their children. Also, it reduces negative parent-child interactions and parenting stress, as well as reactivity response to the children's problematic characteristics (Corthorn, 2018). Based on studies (Kamali, Vaghee, Asgharipour, 2016), 
emotional instability in mothers of children with behavioral disorders causes them to experience behavioral instability, poor control over emotions, chronic feelings of absurdity, and mood swings, frequent and severe responses to emotional stimuli and disruption the interpersonal relationships. Improvement in parental skills for being better able to manage challenges about their children may affect the consequences of children and their parents.

Several limitations of the present study should be noted First, this study is limited to girls and it is unwise to generalize the results to boys. Second, it does not have the followup stage. Third, reinforcing the aura effect of being a curative researcher, may have affected the results of the study. Fourth, this study did not distinguish attachment styles and paternal influences on children. $t$ is recommended that the same study be conducted on boys. For future studies, it is suggested that a follow-up period to be considered, treatment to be done by persons other than the researchers.

\section{Conclusion}

Therefore, considering these limitations, the findings of the study provide important and significant results regarding the effectiveness of mindfulness-based cognitive therapy compared to emotion regulation on reducing externalizing disorder and increasing self-efficacy in children. Therefore, based on the results, mindfulness-based cognitive therapy is considered as a useful therapy that can be used by counselors and therapists.

\section{Ethical Considerations}

\section{Compliance with ethical guidelines}

All ethical principles were considered in this article. The study participants were informed about the purpose of the research and its implementation stages. They were also assured about the confidentiality of their information. Moreover, they were allowed to discontinue participation in the study whenever they wish. Eventually, if desired, the results of the research would be available to them. The present study is the result of a doctoral dissertation in General Psychology (Code 11920705971012) that was approved by the Research Committee of Azad University, Ardebil, Iran.

\section{Funding}

This article was extracted from $\mathrm{PhD}$. thesis of the first author in Department of Psychology, Ardabil Branch, Islamic Azad University, Ardabil, Iran. [Code: 11920705971012].

\section{Authors' contributions}

Methodology: Reza Kazemi; Writing the original draft: Afsane Shokri; Writing, review, and editing: Reza Kazemi; Resources: Somayye Taklavi; Supervision: Mohammad Narimani; Conceptualization, investigation, funding acquisition: All authors.

\section{Conflict of interest}

The authors declared no conflict of interest.

\section{References}

Achenbach, T. M. (1991b). Manual for the teacher's report form/ 4-18 and 1991 profile. Burlington, VI: University of Vermont Department of Psychiatry. [https://books.google.com/ books?id=I5btOwAACAAJ\&dq]

Achenbach, T.M., \& Rescola, L.A. (2001). Manual for the ASEBA school age: Form \& profiles. Burlington, VT: University of Vermont, Department of Psychiatry. [https://www.nctsn.org/ measures/child-behavior-checklist-ages-6-18]

Akhlaghi Yazdi Nejad, F., Hossein Sabet, F., \& Borjali, A. (2017) Effectiveness of emotion regulation training on increasing self-efficacy and well-being in drug-dependent individuals. Journal of Occupational Health and Epidemiology, 6(1), 9-16. [DOI:10.18869/acadpub.johe.6.1.9]

Aldao, A., Nolen-Hoeksema, S., \& Schweizer, S. (2010). Emotion-regulation strategies across psychopathology: A metaanalytic review. Clinical Psychology Review, 30(2), 217-37. [DOI:10.1016/j.cpr.2009.11.004] [PMID]

Allameh, A., Shehni Yeilagh, M., Haji Yakhchali, A. R., \& Mehrabizadeh Honarmand, M. (2015). [The comparison of self-efficacy in peer interaction and social competence of male students with aggressive and normal behaviors (Persian)]. Social Cognition, 4(2), 102-23. http://sc.journals.pnu.ac.ir/article_2241_4. html

Anbari, Kh., Mahdavian, A., \& Nadri, S. (2014). [Predictive factors of mother-child communication patterns in the mothers referred to Khorramabad Shahid Madani Hospital in 2012 (Persian)]. Yafteh, 15(5), 13-22. http://yafte.lums.ac.ir/article1-1489-en.htm

Antony, P. M., \& Manikandan, K. (2015). Role of Self-efficacy and Family environment in regulating Psychological Well being of adolescents and adolescent male offenders undergoing trial. Journal of Contemporary Psychological, 3(2), 87-96.

Arabian, A., Kodapanahi, M. K., Hedari, M., \& Saleh Sedghpour B. (2005). [Relationships between self efficasy beliefs, mental health and health and academic in colleagues (Persian)]. Journal of Psychology, 4(32), 360-71.

Bader, S. H., Barry, T. D., \& Hann, J. A. H. (2015). The relation between parental expressed emotion and externalizing behaviors in children and adolescents with an autism spectrum disorder. Focus on Autism and Other Developmental Disabilities, 30(1), 23-34. [DOI:10.1177/1088357614523065] 
Beirami, M., Hashemi, T., Bakhshi Pour, A., Mahmoud Alilou, M., \& Eghbali, A. (2014). [Comparison of the effects of two methods of cognitive emotion regulation training and mindfulness-based cognitive therapy on psychological distress and cognitive emotion regulation strategies of mothers of mentally retarded children (Persian)]. Journal of Psychology (Tabriz University), 9(33), 43-59. https://psychologyj.tabrizu.ac.ir/ article_3966.html

Bögels, S. M., Hellemans, J., van Deursen, S., Römer, M., \& van der Meulen, R. (2014). Mindful parenting in mental health care: Effects on parental and child psychopathology, parental stress, parenting, Coparenting, and marital functioning. Mindfulness, 5(5), 536-51. [DOI:10.1007/s12671-013-0209-7]

Bögels, S., Hoogstad, B., van Dun, L., de Schutter, S., \& Restifo, K. (2008). Mindfulness training for adolescents with externalizing disorders and their parents. Behavioural and Cognitive Psychotherapy, 36(2), 193-209. [DOI:10.1017/S1352465808004190]

Borjali, A. (2013). [The effectiveness of Mindfulness Based on Cognitive Therapy (MBCT) on reducing the child-parental conflicts in adolescences (Persian)]. International Journal of Behavioral Sciences, 7(1), 1-6. http://www.behavsci.ir/article $67805 . \mathrm{html}$

Camodeca, M., \& Goossens, F. A. (2005). Aggression, social cognitions, anger and sadness in bullies and victims. The Journal of Child Psychology and Psychiatry, 46(2), 186-97. [DOI:10.1111/ j.1469-7610.2004.00347.x] [PMID]

Chew, B. H., Zain, A. M., \& Hassan, F. (2013). Emotional intelligence and academic performance in first and final year medical students: A cross-sectional study. BMC Medical Education, 13, 44. [DOI:10.1186/1472-6920-13-44] [PMID] [PMCID]

Corthorn, C. (2018). Benefits of mindfulness for parenting in mothers of preschoolers in Chile. Frontiers in Psychology, 9, 1443. [DOI:10.3389/fpsyg.2018.01443] [PMID] [PMCID]

Crick, N. R., \& Dodge, K. A. (1996). Social information-processing mechanisms in reactive and proactive aggression. Child Development, 67(3), 993-1002. [DOI:10.2307/1131875] [PMID]

Crick, N. R., \& Grotpeter, J. K. (1995). Relational aggression, gender, and social-psychological adjustment. Child Development, 66(3), 710-22. [DOI:10.2307/1131945] [PMID]

David, O. A., David, D., \& Dobrean, A. (2014). Efficacy of the rational positive parenting program for child externalizing behavior: Can an emotion regulation enhanced cognitive behavioral parent program be more effective than a standard one? Journal of Evidence-Based Psychotherapies, 14(2), 159-78. https:/ / www.researchgate.net/publication/281925831

Esehaghzadeh, F., Reyhani, T., Moharari, F \& Mazlom, S. R. (2018). [Effect of training positive parenting program on mother-child relationship among mothers of children with externalizing disorders (Persian)]. Evidence Based Care Journal, 8(2), 58-66. [DOI: 10.22038/EBCJ.2018.31024.1770]

Farrell, A. D., Bettencourt, A., Mays, S., Kramer, A., Sullivan, T., \& Kliewer, W. (2012). Patterns of adolescents' beliefs about fighting and their relation to behavior and risk factors for aggression. Journal of Abnormal Child Psychology, 40(5), 787-802. [DOI:10.1007/s10802-011-9609-0] [PMID]

Fitzpatrick, S. E., Srivorakiat, L., Wink, L. K., Pedapati, E. V., \& Erickson, C. A. (2016). Aggression in autism spectrum disorder: Presentation and treatment options. Neuropsychiatric Dis- ease and Treatment, 12, 1525-38. [DOI:10.2147/NDT.S84585] [PMID] [PMCID]

Gavița, O. A., David, D., Bujoreanu, S., Tiba, A., \& Ionuțiu, D. R. (2012). The efficacy of a short cognitive-behavioral parent program in the treatment of externalizing behavior disorders in Romanian foster care children: Building parental emotionregulation through unconditional self- and child-acceptance strategies. Children and Youth Services Review, 34(7), 1290-7. [DOI:10.1016/j.childyouth.2012.03.001]

Gottheil, N. F., \& Dubow, E. F. (2001). Tripartite beliefs models of bully and victim behavior. Journal of Emotional Abuse, 2(2-3), 25-47. [DOI:10.1300/J135v02n02_03]

Gowdini, R., Pourmohamdreza-Tajrishi, M., Tahmasebi, S., \& Biglarian, A. (2017). [Effect of emotion management training to mothers on the behavioral problems of offspring: Parents' view (Persian)]. Archives of Rehabilitation, 18(1), 13-24. [DOI:10.21859/jrehab-180113]

Gross, J. J. (2007). Handbook of emotion regulation. New York: Guilford Press. [https:/ / books.google.com/books?id=Jh81lZKqF H8C\&printsec $=$ frontcover\&dq]

Hamidian, S., Omidi, A., Naziri, Gh., Abolghasemi, R., \& Musavinasab, M. (2016). [The effectiveness of mindfulnessbased cognitive therapy on severity of depression and anger in dysthymic patients (Persian)]. Journal of Psychological Studies, 12(3), 83-102. [DOI:10.22051/PSY.2016.2602]

Hillgaar, S. D. (2011). [Mindfulness and self regulated learning (English)] [MSc. thesis]. Trondheim: The University of Science and Technology. https://pdfs.semanticscholar.org/c82 4/2b1a3856a7f981fcc827f382c32be38b87f8.pdf

Hosseinzadeh, Z., Kakavand, A. R., \& Ahmadi, A. (2016). [The mediating role of mother's mindfulness and family resilience on the relationship between behavior problems of children with autism and mothers' psychological well-being (Persian)]. Psychology of Exceptional Individuals, 6(23), 151-78. [DOI:10.22054/JPE.2016.7371]

Hubbard, J. A., McAuliffe, M. D., Morrow, M. T., \& Romano, L. J. (2010). Reactive and proactive aggression in childhood and adolescence: Precursors, outcomes, processes, experiences, and measurement. Journal of Personality, 78(1), 95-118. [DOI:10.1111/j.1467-6494.2009.00610.x] [PMID]

Jacob, C., Gross-Lesch, S., Jans, T., Geissler, J., Reif, A., \& Dempfle, A., et al. (2014). Internalizing and externalizing behavior in adult ADHD. ADHD Attention Deficit and Hyperactivity Disorders, 6(2), 101-10. [DOI:10.1007/s12402-014-0128-z] [PMID]

Jarareh, J., Mohammadi, A., Nader, M., \& Moosavian, S. A (2016). The impact of group play therapy on creativity and control of aggression in preschool children. Cogent Psychology, 3(1), 1264655. [DOI:10.1080/23311908.2016.1264655]

Kamali, A., Vaghee, S., Asgharipour, N., \& Behnam Vashani, H. R. (2016). [The impact of emotion regulation training on mental health in mothers of children with attention deficit/ hyperactivity disorder (Persian)]. Journal of Torbat Heydariyeh University of Medical Sciences, 4(3), 16-23. http://jms.thums. ac.ir/article-1-391-en.html

Kim, Y. W., Lee, S. H., Choi, T. K., Suh, S. Y., Kim, B., \& Kim, C. M., et al. (2009). Effectiveness of mindfulness-based cognitive therapy as an adjuvant to pharmacotherapy in patients with panic disorder or generalized anxiety disorder. Depression $\mathcal{E}$ Anxiety, 26(7), 601-6. [DOI:10.1002/da.20552] [PMID] 
Krueger, R. F., Markon, K. E., Patrick, C. J., \& Iacono, W. G. (2005). Externalizing psychopathology in adulthood: A dimensional-spectrum conceptualization and its implications for DSM-V. Journal of Abnormal Psychology, 114(4), 537-50. [DOI:10.1037/0021-843X.114.4.537] [PMID] [PMCID]

Leff, S. S., \& Crick, N. R. (2010). Interventions for relational aggression: Innovative programming and next steps in research and practice. School Psychology Review, 39(4), 504-7. [PMID] [PMCID]

Liorca, A., Richaud, M. C., \& Malonda, E. (2017). Parenting, peer relationships, academic self-efficacy, and academic achievement: Direct and mediating effects. Frontiers in Psychology, 8, 2120. [DOI:10.3389/fpsyg.2017.02120] [PMID] [PMCID]

Mace, C. (2008). Mindfulness and mental health: Therapy, theory and science. New York: Routledge. https://books.google.com/ books?id=hVWPAgAAQBAJ\&dq

Mehrabi Zadeh Honarmand, M., Abolghasemi, A., Najjarian, B., \& Shokrkon, H. (2000). [Epidemiological evaluation of test anxiety and its relationship with self-efficacy and locus of control according to intelligence variable (Persian)]. Journal of Educational Sciences, 7(1-2), 55-72. http://ensani.ir/fa/ article/83474/

Messmer, P. R., Rodrigues, S., Adams, J., Wells-Gentry, J., Washburn, K., \& Zabaleta, I., et al. (1997). Effect of kangaroo care on sleep time for neonates. Pediatric Nursing, 23(4), 408-14. [PMID]

Minaei, A. (2007). [Factorial invariance of syndromes' items of Achenbach's Child Behavior Checklist (CBCL) (Persian)]. Educational Psychology, 3(7), 93-116. [DOI:10.22054/ JEP.2007.6005]

Narimani, M., Soleymani, E., \& Abolghasemi, A. (2012). [A comparison of internal and external dimensions of thinking styles in blind and sighted students (Persian)]. Journal of School Psychology, 1(1), 108-18. http://jsp.uma.ac.ir/article_24.html

Naseh, A., Heydarinasab, L., \& Shairi, M. R. (2016). The efficacy of mindfulness-based intervention for adolescents with attention deficit/hyperactivity symptoms and externalizing problems on reducing mother-adolescent conflict. International Journal of Applied Behavioral Sciences, 3(3), 15-22. http://journals.sbmu.ac.ir/ijabs/article/view/17694

Parent, J., McKee, L. G., Rough, J. N., \& Forehand, R. (2016). The association of parent mindfulness with parenting and youth psychopathology across three developmental stages. Journal of Abnormal Child Psychology, 44(1), 191-202. [DOI:10.1007/ s10802-015-9978-x] [PMID] [PMCID]

Patterson, G. R., DeBaryshe, B. D., \& Ramsey, E. (1989). A developmental perspective on antisocial behavior. American Psychologist, 44(2), 329-35. [DOI:10.1037/0003-066X.44.2.329] [PMID]

Perry, D. G., Perry, L. C., \& Rasmussen, P. (1986). Cognitive social learning mediators of aggression. Child Development, 57(3), 700-11. [DOI:10.2307/1130347] [PMID]

Pompili, M., Innamorati, M., Lester, D., Brunetti, S., Tatarelli, R., \& Girardi, P. (2007). Gender effects among undergraduates relating to suicide risk, impulsivity, aggression and selfefficacy. Personality and Individual Differences, 43(8), 2047-56. [DOI:10.1016/j.paid.2007.06.019]
Rayan, A., \& Ahmad, M. (2018). Mindfulness and parenting distress among parents of children with disabilities: A literature review. Perspectives in Psychiatric Care, 54(2), 324-30. [DOI:10.1111/ppc.12217] [PMID]

Riahi, M., Esmaeili, M., \& Kazemian, S. (2016). [The effects of mothers' mindfulness training on children's self-efficacy (Persian)]. Journal of Developmental Psychology (Iranian Psychologists), 12(48), 367-75. http://jip.azad.ac.ir/article_524884.html

Roberton, T., Daffern, M., \& Bucks, R. S. (2012). Emotion regulation and aggression. Aggression and Violent Behavior, 17(1), 72-82. [DOI:10.1016/j.avb.2011.09.006]

Samek, D. R., \& Hicks, B, M. (2014). Externalizing disorders and environmental risk: Mechanisms of gene-environment interplay and strategies for intervention. Clinical Practice (London, England), 11(5), 537-47. [DOI:10.2217/cpr.14.47] [PMID] [PMCID]

Samson, J. E. (2009). The role of perceived self-efficacy in controlling behavior [MSc. thesis]. Nashville, TN: Vanderbilt University. https:/ / etd.library.vanderbilt.edu/available/etd-07242009122514/unrestricted/final_thesis.pdf

Satoorian, S. A., Tahmassian, K., \& Ahmadi, M. R. (2017). [The role of parenting dimensions and child-parent relationship in children's internalized and externalized behavioral problems (Persian)]. Journal of Family Research, 12(4), 683-705. http:/ /jfr. sbu.ac.ir/article/view/4978

Schultz, D. P., \& Schultz, S. E. (2006). Theories of personality [Y. Seyed Mohammadi, Persian Trans]. $8^{\text {th }}$ Ed. Tehran: Virayesh. http://opac.nlai.ir/opac-prod/bibliographic/614897

Scott, J. G., Tunbridge, M., \& Stathis, S. (2018). The aggressive child. Journal of Paediatrics and Child Health, 54(10), 1165-9. [DOI:10.1111/jpc.14182] [PMID]

Segal, Z. V., Williams, J. M. G., \& Teasdale, J. D. (2002). Mindfulness-based cognitive therapy for depression: A new approach to preventing relapse. New York: Guilford Publication. https:// books.google.com/books?id=_QJ3cQT5UPsC\&dq

Shahim, S. (2007). [Relational aggression in preschool children (Persian)]. Iranian Journal of Psychiatry and Clinical Psychology, 13(3), 264-71. http://ijpcp.iums.ac.ir/article-1-272-en.html

Shearer, A., Hunt, M., Chowdhury, M., \& Nicol, L. (2016). Effects of a brief mindfulness meditation intervention on student stress and heart rate variability. International Journal of Stress Management, 23(2), 232-54. [DOI:10.1037/a0039814]

Sherer, M., \& Adams, C. H. (1983). Construct validation of the self-efficacy scale. Psychological Reports, 53(3), 899-902. [DOI:10.2466/pr0.1983.53.3.899]

van Aken, C., Junger, M., Verhoeven, M., van Aken, M. A. G, Deković, M., \& Denissen, J. J. A. (2007). Parental personality, parenting and toddlers' externalizing behaviors. European Journal of Personality, 21(8), 993-1015. [DOI:10.1002/per.643]

Walsh, M. (2013). A study of children's emotion regulation, coping and self-efficacy beliefs [PhD. thesis]. London: Institute of Education, University of London. https://discovery.ucl. ac.uk/id/eprint/10020730/

Waters, S. F., Virmani, E. A., Thompson, R. A., Meyer, S., Abigail Raikes, H., \& Jochem, R. (2010). Emotion regulation and attachment: Unpacking two constructs and their association. 
Journal of Psychopathology and Behavioral Assessment, 32(1), 3747. [DOI:10.1007/s10862-009-9163-z] [PMID] [PMCID]

Weijers, D., van Steensel, F. J. A., \& Bögels, S. M. (2018). Associations between psychopathology in mothers, fathers and their children: A structural modeling approach. Journal of Child and Family Studies, 27(6), 1992-2003. [DOI:10.1007/s10826-0181024-5] [PMID] [PMCID]

Werner, N. E., \& Nixon, C. L. (2005). Normative beliefs and relational aggression: An investigation of the cognitive bases of adolescent aggressive behavior. Journal of Youth and Adolescence, 34(3), 229-43. [DOI:10.1007/s10964-005-4306-3]

Woodruff, S. L., \& Cashman, J. F. (1993). Task, domain, and general efficacy: A reexamination of the self-efficacy scale. Psychological Reports, 72(2), 423-32. [DOI:10.2466/pr0.1993.72.2.423]

Yazdkhasti, F., \& Oreyzi, H. R. (2011). [Standardization of child, parent and teacher's forms of child behavior checklist in the city of Isfahan (Persian)]. Iranian Journal of Psychiatry and Clinical Psychology, 17(1), 60-70. http://ijpcp.iums.ac.ir/article1-1318-en.html

Yin, H., Han, J., \& Perron, B. E. (2020). Why are Chinese university teachers (not) confident in their competence to teach? The relationships between faculty-perceived stress and self-efficacy. International Journal of Educational Research, 100, 101529. [DOI:10.1016/j.ijer.2019.101529]

Zhang, W., Wang, M., \& Ying, L. (2019). Parental mindfulness and preschool children's emotion regulation: The role of mindful parenting and secure parent-child attachment. Mindfulness, 10, 2481-91. [DOI:10.1007/s12671-019-01120-y] 
This Page Intentionally Left Blank 